\begin{tabular}{cc|c}
\hline Tar. Bil. Der. & Tarım Bilimleri Dergisi & Journal of Agricultural Sciences \\
& $\begin{array}{c}\text { Dergi web sayfası: } \\
\text { www.agri.ankara.edu.tr/dergi }\end{array}$ & Journal homepage: \\
& www.agri.ankara.edu.tr/journal
\end{tabular}

\title{
Bal Arısı (Apis mellifera) Ana Arılarının Ege Bölgesi Koşullarında Farklı Yöntemlerle Kışlatılması
}

\author{
Aytül Uçak KOÇa, Mete KARACAOĞLU ${ }^{\mathrm{b}}$ \\ ${ }^{a}$ Adnan Menderes Üniversitesi, Koçarlı Meslek Yüksekokulu, Aydın, TÜRKIYE

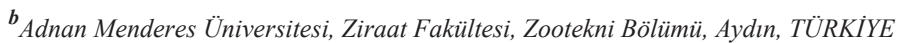

\section{ESER BILGISİ}

Araştırma Makalesi

DOI: 10.1501/Tarimbil_0000001383

Sorumlu Yazar: Aytül Uçak KOÇ, E-posta: aucak@adu.edu.tr, Tel: +90 (256) 7727348

Geliş Tarihi: 04 Kasım 2014, Düzeltmelerin Gelişi: 09 Ocak 2015, Kabul: 02 Şubat 2015

\section{ÖZET}

Aydın'da 2012-2014 yılları arasında yürütülen bu araştırmanın amacı Ege Bölgesi koşullarında bireysel ve kitlesel ana arı (Apis mellifera) kışlatma başarısını karşılaştırmaktır. Ardı sıra 2 yıl Anadolu arısı Ege ekotipi (AE) ve İtalyan ırkından (It) yetiştirilen ana arılar banka kolonilerinde kitlesel ve çiftleştirme kutularında ve ruşetlerde (kontrol) bireysel kışlatılmıştır. Kitlesel kışlatma için birinci yıl AE ve It ırkından ana arılı (ABK) ve ana arısız (ASBK) banka kolonileri, ikinci yıl ise ana arısız banka kolonileri (ASBK) kullanılmıştır. Birinci yıl, her 2 rktan (AE: 4 koloni, It: 4 koloni) 8 banka kolonisinde (ABK: 4 koloni, ASBK: 4 koloni) toplam 112 ana arı, ikinci yıl ise, 4 ASBK (AE: 2 koloni, It: 2 koloni)'de toplam 56 ana arı kitlesel kışlatılmıştır. Her 2 yılda 20 çiftleştirme kutusunda 10 It ve 10 AE ana arı bireysel kışlatılmıştır. Yaklaşık 3 ay süren her kışlatma dönemi sonunda her grupta ana arı yaşama gücü (\%) saptanmıştır. Kitlesel kışlatmanın ana arıların üreme performansını etkileyip etkilemediğini test etmek için birinci yıl kitlesel ve bireysel kışlatılmış ana arılardan rasgele 30'u (banka kolonisi: 10, çiftleştirme kutusu: 10, ruşet: 10) üretim kolonilerine kabul ettirilmiştir. Ana arı yaşama gücü; banka kolonisinin ırkına $(\mathrm{P}>0.05)$ ve kışlatılan ana arının genotipine $(\mathrm{P}>0.05)$ göre değişmemiştir. Fakat banka kolonisinin tipi ana arı yaşama gücünü etkilemiştir $(\mathrm{P}<0.01)$. Birinci yıl, ASBK' da kışlatılan ana arıların \% 64.3'ü, ABK'da kışlatılan ana arıların ise \% 17.9'u kıştan çıkabilmiştir ( $\mathrm{P}<0.01)$. Her 2 yılda da banka kolonilerinde ana arı yaşama gücü (\% 64.3 ve \% 71.5) çiftleştirme kutularında yaşama gücüne (\% 100 ve \% 100) göre daha düşük $(\mathrm{P}<0.01)$ bulunmuştur. Kitlesel kışlatılan ana arıların test kolonilerinde yumurtlama performansları bireysel kışlatılanlardan farklı bulunmamıştır $(\mathrm{P}>0.05)$.

Anahtar Kelimeler: Bal arısı; Ana arı; Banka kolonisi; Kitlesel depolama; Kışlatma; Ege Bölgesi

\section{Overwintering of Honey Bee Queens (Apis mellifera) by Different Methods under Aegean Region Conditions}

\section{ARTICLE INFO}

Research Article

Corresponding Author: Aytül Uçak KOÇ, E-mail: aucak@adu.edu.tr, Tel: +90 (256) 7727348

Received: 04 November 2014, Received in Revised Form: 09 January 2015, Accepted: 02 February 2015 


\begin{abstract}
This study was conducted between 2012-2014 years in Aydın province to compare the success of individual and mass storage of mated honey bee queens (Apis mellifera) under the winter conditions of Aegean region. The queens reared from Italian (It) and Aegean ecotype of Anatolian (AE) honey bee races in 2 consecutive years were overwintered en masse in reservoir colonies and individually in colonies held in Kirchain mating boxes and 5-frame nucleus hives (control group). In the first year, both queenright reservoir (QRR) and queenless reservoir (QLR) colonies were prepared from both naturally mated It and AE queens for mass storage, whereas only queenless reservoir (QLR) colonies from both races were used in the second year. A total of 112 mated queens were stored both in 4 QRR and 4 QLR in the first year, whereas a total of 56 mated queens were stored only in 4 QLR in the second year. In both years, 10 It and $10 \mathrm{AE}$ queens were individually overwintered in 20 mating boxes. At the end of about 3-month overwintering period in both years, queen survival (\%) was determined in all experimental groups. In order to test whether mass storage affected the reproductive performance of queens, 30 queens overwintered in the first year in reservoir colonies (10 queens), mating boxes (10 queens) and nucleus hives (10 queens) were introduced into test colonies. The queen survival (\%) was not affected by both the race of reservoir colony $(\mathrm{P}>0.05)$ and of the queen overwintered $(\mathrm{P}>0.05)$. But, the type of reservoir colony affected queen survival $(\mathrm{P}<0.01)$. In the first year, $64.3 \%$ of queens stored in QLR colonies survived for 3 months, whereas $17.9 \%$ of queens survived in $\mathrm{QRR}$ colonies $(\mathrm{P}<0.01)$. In both years, the queen survivals in reservoir colonies (64.3\% and $71.5 \%$ in QLR colonies) were lower than those in colonies held in mating boxes $(100 \%$ and $100 \%$; $\mathrm{P}<0.01)$. The reproductive performances of queens stored in reservoir colonies were not found different from those of individually overwintered queens in test colonies $(\mathrm{P}>0.05)$.
\end{abstract}

Keywords: Honey bee; Queen; Reservoir colony; Mass storage; Overwintering; Aegean Region

(C) Ankara Üniversitesi Ziraat Fakültesi

\section{Giriş}

Ana arı yetiştiriciliğinin olanaklı olmadığı yılın kritik zamanlarında, ana arı gereksiniminin karşılanması için bir önceki yıl yetiştirilen ana arıların kitlesel olarak banka kolonilerinde, bireysel olarak da çiftleştirme kutularında kışlatılması mümkündür. Ana arıların kitlesel olarak banka kolonilerinde depolanması biyolojik ve ekonomik olarak uygun bir sistemdir (Levinsohn \& Lensky 1981; Wyborn et al 1993; Gençer 2003). Banka kolonilerinde ana arıları kitlesel kışlatmanın başarısı; banka kolonisinin çok güçlü olması, ana arısız olması, iyi beslenmesi ve iyi bir yalıtımın sağlanmasına bağlıdır (Wyborn et al 1993).

Bankalama başarısının göstergesi, ana arıların banka kolonilerinde depolanması sirasinda ve sonrasında yaşayan ana arı oranının (ana arı yaşama gücü) yüksek olmasıdır. Yumurtlayan genç ana arıların, yazın kısa süre, kışın ise uzun süre (3-5 ay) kitlesel olarak banka kolonilerinde depolanması üzerine başarılı sonuçlar elde edilmiştir (Levinsohn \& Lensky 1981; Dietz et al 1983; Wyborn et al 1993;
Gençer 2003). Dietz et al (1983), kışın bankalanan ana arıların 3 aylık süreçte \% 89.6'sının, sonraki 38 günlük süreçte ise hızlı bir azalma sonucu, \% 46.4'ünün yaşadığını bildirmişlerdir. Levinsohn \& Lensky (1981), subtropik iklim koşullarında ana arısız banka kolonilerinde ekim-kasım aylarında depolanan çiftleşmiş ana arılardan yaşayanların oranını ilk yıl \% 35, ikinci, üçüncü ve dördüncü yılda ekim-şubat aylarında 5 ay boyunca depolanan ana arılardan yaşayanların oranını sırasıyla; \% 57, $\% 81$ ve \% 86 olarak bildirmişlerdir. Aynı araştırıcılar, yaz aylarında (Mayıs-Ağustos) iki ana arılı banka kolonilerinin ballık bölümünde 2 ay depolanan ana arıların \% 78'inin yaşadığını bildirmişlerdir. Wyborn et al (1993), ana arıları kış boyunca banka kolonilerinde kitlesel depolamışlar, ana arı ızgarasından yapılan kafeslerdeki ana arıların yaşama oranını en fazla $\% 25$, ahşaptan yapılmış ve telle kaplanmış bireysel kafeslerde tutulan ana arısız banka kolonilerinde yaşama oranını ise ortalama $\% 60$ olarak belirlemişlerdir.

Türkiye'de ana arıların kitlesel kışlatılması üzerine ilk çalışma, Gençer (2003) tarafından 
yapılmıştır. Yılın kritik zamanlarında ana arı gereksinimini karşılamanın önemini vurgulayan araştırıcı, banka kolonilerinde ana arıları kışlatmak için başarılı bir yöntem tasarlamıştır. Araştırıcı, karasal iklim koşullarında 5 ay boyunca, ana arıları 2 farklı şekilde tasarlanmış banka çerçevesinde, ana arılı ve ana arısız banka kolonilerinde kitlesel, çiftleştirme kutularında bireysel kışlatmıştır. Gençer (2003), ana arılı banka kolonilerinde depolanan tüm ana arıların öldüğünü, ana arısız banka kolonilerinde üzeri elek teli ile kapatılmış doğal petekli banka çerçevesinde kışlatılmış ana arıların $\%$ 40.5'inin, elek telli bireysel kafese yerleştirilmiş banka çerçevesinde kışlatılmış ana arıların ise $\% 16.7$ 'sinin 5 ay yaşayabildiğini bildirmiştir.

Banka kolonilerinde başarılı bir şekilde depolanan ana arıların koloniye kabul edildikten sonraki performansları da önemlidir. Woyke (1988) depolanan ana arıların bankalama uygulamasından zarar gördügünü ve performanslarının düşük olduğunu belirtirken, bazı araştırıcılar da (Shehata 1982; Wyborn et al 1993; Gençer 2003) bankalamanın ana arıların performanslarını olumsuz etkilemediğini bildirmişlerdir.

Ege Bölgesi, sahip olduğu iklim özellikleri ve florasıyla yılın büyük bölümünde ana arı yetiştiriciliğine uygun bir bölgedir. Akdeniz iklim koşullarına sahip olan Güney Ege'de ana arı yetiştiriciliği mart ayından başlayarak ekim ayına kadar sürdürülebilmektedir (Uçak-Koç \& Karacaoğlu 2004; 2005; 2011). Ana arı talebinin yoğun olduğu dönem, bölgede genel olarak şubat ayının sonu ile mart ayının başlarıdır. Bölgede, ana arı yetiştiren işletmeler ve ana arı gereksinimini işletmesinden karşılayan arıcılar için ekonomik ve kolay bir depolama yönteminin belirlenmesi önemlidir. $\mathrm{Bu}$ çalışmada, 2 farklı genotipten denetimli yetiştirilmiş ana arıları, ana arılı banka kolonileri (ABK) ve ana arısız banka kolonileri (ASBK)'nde kitlesel ve çiftleştirme kutularında bireysel kışlatmanın başarısını (kışlatılan ana arılardan ilkbahara canlı çıkanların oranı) ve kıştan canlı çıkan ana arıların koloni performanslarını Ege Bölgesi koşullarında belirlemek amaçlanmıştır. Araştırmada ayrıca bireysel ve kitlesel kışlatılmış ana arıların üretim kolonilerinde yumurtlama performansları karşılaştırılmıştır.

\section{Materyal ve Yöntem}

\subsection{Materyal}

Araştırma, Ege Bölgesi'nin güneyinde yer alan Aydın İli'nde Adnan Menderes Üniversitesi Ziraat Fakültesi araştırma arılığında 2012-2014 yılları arasında yapılmıştır. Araştırmanın canlı materyalini oluşturan ana arılar; yapay tohumlanmış damızlık İtalyan arıs1 (It; $A$. m. ligustica) ve Anadolu arıs1 Ege ekotipi (AE; A. m. anatoliaca) kolonilerinden aşılama yöntemiyle yetiştirilmiş ve doğal çiftleşmiştir.

\subsection{Yöntem}

$\mathrm{Bu}$ çalışmada yumurtlayan genç ana arılar, banka kolonilerinde kitlesel ve çiftleştirme kutularında bireysel (normal koloni düzeninde) yaklaşı 3 ay kışlatılmıştır. Banka kolonilerinin ana arıları, çiftleştirme kutularında ve ruşetlerde (kontrol grubu) tutulan kolonilerin ana arıları ve banka kolonilerinde depolanan ana arılar, yapay tohumlama ile saflığ 1 korunan It ve AE kolonilerinden seçilen birer damızlık koloniden larva transferi ile mayıs-haziran aylarında yetiştirilmiştir. Her 2 genotipten yetiştirilen ana arılar aynı yörede doğal çiftleştirilmiş, bunlardan birkaçı banka kolonisi olarak hazırlanan yeni kolonilere verilmiştir. Banka kolonilerinde, çiftleştirme kutularında ve ruşetlerde kışlatılacak ana arılar ise kışlatmaya kadar çiftleştirme kutularında tutulmuşlardır.

Araştırmanın birinci yılında (2012-2013), ana arılı (ABK) ve ana arısız (ASBK) olmak üzere toplam 8 banka kolonisi kullanılmıştır. Bu banka kolonilerinin hazırlık aşamasında, 4 ABK'nın 2'sine It, diğer 2'sine ise AE ana arısı, aynı şekilde 4 ASBK'nın 2'sine It, diğer 2'sine de AE ana arısı kabul ettirilmiştir. Banka kolonilerinin her birinde 14 ana arı olmak üzere toplam 112 ana arı depolanmıştır. It ve $A E$ ana arıların bireysel kışlatılması için 20 çiftleştirme kutusu (10 It ve $10 \mathrm{AE}$ ) kullanılmıştır. Ayrıca kitlesel kışlatmanın başlangıcından 8 hafta önce 10 ruşet kolonisinden 5 'ine It, diğer 5 'ine 
ise $\mathrm{AE}$ ana arısı kabul ettirilmiştir. Ana arılar; çiftleştirme kutularında ve ruşetlerde bireysel, banka kolonilerinde kitlesel olarak Kasım ayının ikinci haftasından (2012) Şubat ayının ilk haftasına kadar (2013) kışlatılmışlardır.

Banka kolonilerinde kışlatılan ana arılar, kış mevsimi boyunca $4 \mathrm{kez}$ denetlenmiş ve kolonilere 2 kez kapalı yavrulu petek takviyesi yapılmışıtır. Banka kolonilerinin denetlendiği günlerde çiftleştirme kutuları da denetlenmiştir. Kışlatma süresince, yaklaşık olarak 10 günde bir her banka kolonisine $500 \mathrm{~g}$, her çiftleştirme kutusuna $100 \mathrm{~g}$ kek verilmiştir.

Araştırmanın birinci yılında, ana arısız banka kolonilerinde kitlesel kışlatılan ana arılardan yaşayanların oranının benzer iklim koşullarında yapılan bir çalışmada elde edilen sonuçlara (Levinsohn \& Lensky 1981) göre daha düşük olmas1 nedeniyle, ASBK'da kitlesel kışlatma 1 yıl daha denenmiştir. Ancak, ABK'da kitlesel kışlatılan ana arıların birçoğunun (\% 82) ölmesi ve bu bulgunun literatür ile uyumlu olması (Gençer 2003) nedeniyle ikinci yıl ABK'da kitlesel kışlatmayı tekrarlamak gerekli görülmemiştir. Buna bağlı olarak ikinci yıl, 4 ASBK'da (2 It ve 2 AE) kitlesel kışlatma ve 20 çiftleştirme kutusunda bireysel kışlatma (Kasım 2013-Şubat 2014) yapılmıştır.

\subsubsection{Banka kolonilerinin hazırlanması}

Nisan ayında yetiştirilen ana arılardan mayıs ayında yeni koloniler oluşturulmuştur. Bu kolonilerin yaz boyunca bakım ve beslemeleri yapılmış, ağustos ayının sonundan kasım ayına kadar iki ana arılı olarak yönetilmişlerdir. İki ana arılı yönetilen kolonilerden 4'ünün her 2 ana arısı, diğer 4'ünün ise sadece kuluçkalık bölümündeki ana arısı kovanlarından alınarak ASBK ve ABK hazırlanmıştır. Bu uygulamadan 5 gün sonra, ana arı kafes blokları banka kolonilerine yerleştirilmiştir. Kafes blokları yerleştirilmeden hemen önce, ABK'nın ana arısı ballık bölümüne ana arı 1zgarası ile hapsedilerek ana arı kafes bloğu kuluçkalık bölümünde yavru alanının tam ortasına yerleştirilmiştir. ASBK'da ise ana arısızlık sonucu açık yavrulu peteklerde yapılmış ana arı yüksükleri bozulmuş, ana arı kafes bloğu ABK'da olduğu gibi kuluçkalık bölümünde yavru alanının tam ortasına yerleştirilmiştir. Kasım ayı başında banka kolonileri; yaklaşı $20 \mathrm{~kg}$ bal, 4-5 yavrulu petek ve 14-16 arılı petek, çiftleştirme kutuları; yaklaşık $200 \mathrm{~g}$ ergin arı, 2 ballı ve 2 yavrulu petek, ruşetler ise 5 arılı petek, 1-2 yavrulu petek ve yaklaşık 5-6 kg bal içerecek şekilde düzenlenmişlerdir.

\subsubsection{Ana arı kafes bloklarının hazırlanması}

Bankalanacak ana arılar çiftleştirme kutularından toplandıktan sonra üzeri $2 \mathrm{~mm}$ gözenekli elek teli ile kaplanmış ahşap kafeslere $(6 \times 4 \times 2 \mathrm{~cm})$ tek tek konulmuş ve kafeslerin delikleri kapatılmıştır. Ardından yan yana 7, alt alta 2 kafes bir arada sabitlenerek 14 kafesten oluşan tek blok (28 x 14 $\mathrm{cm})$ haline getirilmiştir. Üst kısmında bal kemeri bulunan bir kuluçkalık peteğinin ortası kafes bloğu boyutunda $(28 \times 14 \mathrm{~cm})$ kesilerek çıkarılmış ve buraya kafes bloğu monte edilmiştir (Gençer 2003).

Ana arıların banka çerçevesindeki konumunun ana arı yaşama gücüne etkisini belirlemek için ana arılar kafes bloklarına 2 farklı düzende yerleştirilmiştir. Birincisinde, kafes bloğunun üst bölümünden başlayarak farklı genotip ana arılar yan yana getirilerek kafes bloğuna dizilmiştir. İkincisinde ise, genotiplerden biri kafes bloğunun üst bölümüne diğeri de alt bölüme dizilmiştir. Banka çerçeveleri banka kolonilerine yerleştirilirken her bir banka kolonisi tipi (ABK ya da ASBK) ve her bir genotipi (It ya da AE) temsil eden 2 banka kolonisinden her birinde 2 farklı kafes bloğu düzeninden birinin olması sağlanmıştır.

\subsubsection{Kitlesel ve bireysel kışlatılmış ana arıların yumurtlama performansı}

Araştırmanın birinci yılında kışlatmadan canlı çıkan ana arıların yumurtlama performanslarını belirlemek için her gruptan (banka kolonisi ve çiftleştirme kutusu) rastgele 5 It ve $5 \mathrm{AE}$ ana arı (toplam 20 ana arı) seçilmiştir. Bu ana arılar 2013 yılı Mart ayının ilk haftasında her biri 1.5-2 yavrulu petek, 4-4.5 arılı petek içeren 20 koloniye kabul ettirilmiştir. Ergin arı ve yavru bakımından aynı/ benzer kondisyona sahip It ve AE ana arll 5'er 
ruşet ise (toplam 10 ruşet) kontrol grubu olarak teste dahil edilmiştir. Test (üretim) kolonileri (30 koloni) Mayıs ayına kadar şeker şurubu ile düzenli beslenmiştir. Test kolonilerinin Nisan ayından Ağustos ayına kadar 21 gün arayla toplam $7 \mathrm{kez}$ arılı petek sayıları saptanmıştır. Kitlesel ve bireysel kışlatılan ana arıların yumurtlama performanları arasında farklılık bulunmaması ve bu sonucun literatür ile uyumlu olması (Shehata 1982; Wyborn et al 1993; Gençer 2003) üzerine ikinci y1l kışlatılan ana arıların koloni performanslarının belirlenmesi gerekli görülmemiştir.

\subsection{Istatistik analiz}

Ana arı kışlatma verileri 3 aşamada analiz edilmiştir. Birinci aşamada, yıllara göre ASBK, ABK ve çiftleştirme kutularında kışlatılan ana arıların yaşama oranları $\mathrm{P}<0.05$ önem seviyesinde $\chi^{2}$ testi uygulanarak karşılaştırılmıştır. İkinci aşamada, birinci yılda banka kolonisi tipinin (ABK ve ASBK) ve kışlatılan ana arıların genotipinin (It ve AE) her kontrol gününde (bankalama süresi) yaşayan ana ar1 oranını etkileyip etkilemediği $\mathrm{P}<0.05$ önem seviyesinde $\chi^{2}$ testi uygulanarak belirlenmiştir. Araştırmanın ikinci yılında ise, banka kolonisi genotipinin (It ve AE) bankalama başarısının (her kontrol gününde yaşayan ana arıların oranı) banka kolonisinin genotipine (It ve AE) bağlı olarak değişip değişmediği $\mathrm{P}<0.05$ önem seviyesinde $\chi^{2}$ testi uygulanarak belirlenmiştir. Üçüncü aşamada, birinci yıl ve ikinci yıl ASBK'ne ait ana arı yaşama oranları birlikte analiz edilerek, kışlatma başarısının yıl ve banka kolonisi genotipine göre değişip değişmediği $\mathrm{P}<0.05$ önem seviyesinde $\chi^{2}$ testi uygulanarak belirlenmiştir. Ayrıca, birinci yıl ve ikinci yıl ASBK'nde ana arıların yaşama güçlerini $\left(\mathrm{y}_{\mathrm{i}}\right)$ belirlemek için yaşayanlar 0 , ölenler 1 olarak kodlanmıştır.

$Y_{\imath}=\left\{\begin{array}{cc}0 & \text { yaşadı } \\ 1 & \text { öldü }\end{array}\right.$

Banka kolonisi genotipinin $\left(X_{1}\right)$ ve kafeslenen ana arıların yerleştirme düzeninin $\left(X_{2}\right)$ ana arıların yaşama gücü üzerine etkisini belirlemek için $\mathrm{P}<0.05$ önem seviyesinde lojistik regresyon analizi uygulanmıştır. $\mathrm{Bu}$ analizde, lojistik regresyon eşitliği;

$$
\boldsymbol{\theta}=\frac{e^{\left(\beta_{0}+\beta_{1} X_{1}+\beta_{2} X_{2}\right)}}{1+e^{\left(\beta_{0}+\beta_{1} X_{1}+\beta_{2} X_{2}\right)}}
$$

olup $\theta=P\left(Y_{i}=1\right)=1-P\left(Y_{i}=0\right) \quad$ olasilık değerini, $\beta_{0}$ eşitliğin sabit değerini, $\beta_{1}$ ve $\beta_{2}$ regresyon katsayıları da banka kolonisi genotipinin $\left(X_{1}\right)$ ve bankalanan ana arıların banka çerçevesine yerleştirme düzeninin $\left(X_{2}\right)$ ana arı yaşama gücüne etkilerini belirtmektedir.

Araştırmanın birinci yılında, banka kolonileri, çiftleştirme kutuları ve ruşetlerde kışlatılan ana arıların test kolonilerinde yumurtlama performanslarının ölçüsü olarak kullanılan arılı petek sayısı verileri tekrarlanan deneme düzeninde SAS paket programı ile analiz edilmiştir.

\section{Bulgular ve Tartışma}

Araştırmanın birinci ve ikinci yılında çiftleştirme kutularında bireysel kışlatılan ana arıların tümü (\% 100) yaşarken, kitlesel kışlatmanın yapıldığı ABK ve ASBK'da yaşayan ana arı oranı azalarak devam etmiş, 3 aylık kışlatma sonunda birinci yılda yaşayan ana arı oranı ABK'da \% 17.9, ASBK'da \% 64.3, ikinci yılda ASBK'da \% 71.5 olarak belirlenmiştir (Çizelge 1). Her 2 yılda da kitlesel kışlatılan ana arılardan yaşayanların oranı bireysel kışlatılanlara göre daha düşük $(\mathrm{P}<0.01)$ bulunmuştur.

ABK ve ASBK'da kitlesel kışlatılan ana arılardan yaşayanların oranı karşılaştırıldığında, ABK (\% 17.9) ve ASBK (\% 64.3) arasındaki fark (\% 46.4) önemli $(\mathrm{P}<0.01)$ bulunmuştur (Çizelge 1). Seksen beş gün sonunda It ana arıl1-ABK'de kışlatılan 28 ana arıdan 3'ü (\% 10.7), It ana arılıASBK'de kışlatılan 28 ana arıdan ise 20'si (\% 71.4) yaşarken, AE ana arıl1-ABK'de 28 ana arıdan 7'si (\% 25) ve AE ana arıl1-ASBK'de ise 16 's1 (\% 57.1) yaşamışıtır (Çizelge 1).

Birinci y1l elde edilen veriler doğrultusunda araştırmanın ikinci yılında deneme ASBK ile yürütülmüştür. Kışlama sonunda It ve AE ana arılar 
Çizelge 1- Çiftleştirme kutularında bireysel ve banka kolonilerinde kitlesel kışlatılan ana arıların yaşama gücü (\%)

Table 1- The survival (\%) of queens overwintered individually in mating hives and en mass in reservoir colonies

\begin{tabular}{|c|c|c|c|c|c|c|}
\hline \multirow{3}{*}{$\overline{\text { Birinci yıl denetim günleri }}$} & \multirow{2}{*}{\multicolumn{2}{|c|}{$\begin{array}{c}\text { Bireysel klşlatma } \\
\qquad \zeta K(n=20)\end{array}$}} & \multicolumn{4}{|c|}{ Kitlesel klşlatma ${ }^{\#}$} \\
\hline & & & \multicolumn{2}{|c|}{$A B K(n=56)$} & \multicolumn{2}{|c|}{$\operatorname{ASBK}(n=56)$} \\
\hline & It & $A E$ & It & $A E$ & It & $A E$ \\
\hline & $(n=10)$ & $(n=10)$ & $(n=28)$ & $(n=28)$ & $(n=28)$ & $(n=28)$ \\
\hline 1. gün & 100 & 100 & 98.2 & 96.4 & 100 & 100 \\
\hline 15. gün & 100 & 100 & 89.3 & 89.3 & 92.9 & 92.9 \\
\hline 71. gün & 100 & 100 & $21.4 \mathrm{~A}$ & $39.3 \mathrm{~A}$ & $75.0 \mathrm{~B}$ & $64.3 \mathrm{~B}$ \\
\hline 85. gün & 100 & 100 & $10.7 \mathrm{~A}$ & $25.0 \mathrm{a}$ & $71.4 \mathrm{~B}$ & $57.1 \mathrm{~b}$ \\
\hline Genel & \multicolumn{2}{|c|}{$100 \mathrm{~A}$} & \multicolumn{2}{|c|}{$17.9 \mathrm{~B}$} & \multicolumn{2}{|c|}{$64.3 \mathrm{C}$} \\
\hline \multicolumn{7}{|l|}{ İkinci yıl denetim günleri } \\
\hline 1. gün & 100 & 100 & - & - & 100 & 100 \\
\hline 10. gün & 100 & 100 & - & - & 96.4 & 96.4 \\
\hline 66. gün & 100 & 100 & - & - & 78.6 & 75.0 \\
\hline 83. gün & 100 & 100 & - & - & 75.0 & 67.9 \\
\hline Genel & \multicolumn{2}{|c|}{$100 \mathrm{~A}$} & \multicolumn{2}{|c|}{-} & \multicolumn{2}{|c|}{$71.5 \mathrm{~B}$} \\
\hline
\end{tabular}

A, B, C: P<0.01; a, b: P<0.05; It, İtalyan; AE, Anadolu arısı Ege ekotipi; ÇK, çiftleştirme kutusu, ABK, ana arılı banka kolonisi; ASBK, ana arısız banka kolonisi; \# ABK-It ile ASBK-It ve ABK-AE ile ASBK-AE aynı denetleme gününde karşılaştırılmıştır

ile oluşturulan ASBK'de yaşayan ana arıların oranı sırasıyla; \% 75.0 ve \% 67.9 olarak belirlenmiş, fark önemsiz bulunmuştur (Çizelge 1).

Araştırmanın her 2 yılında ASBK'de ana arı yaşama gücü verilerine uygulanan lojistik regresyon analizine göre, hem banka kolonisi genotipinin hem de ana arıları yerleştirme sırasının kışlatılan ana arıların yaşama gücüne etkisi önemsiz bulunmuştur. Ayrıca ana arı yaşama gücüne yılın etkisi ve genotip $\mathrm{x} y$ yl interaksiyonu önemsiz bulunmuştur. Birinci ve ikinci yıl ASBK verileri birlikte analiz edildiğinde, It ana arıları ve AE ana arıları ile oluşturulan ASBK' de yaşayan ana arı oranları sırasıly \% 73.2 ve $\% 62.5$ olarak saptanmış, fark önemsiz bulunmuştur. Ayrıca ASBK ve çiftleştirme kutularında yaşayan ana arıların genotipinin (AE ve It) yaşama gücüne etkisi önemsiz bulunmuştur.

Bireysel ve kitlesel kışlatılan ana arılar ile oluşturulan koloniler ve kontrol grubu kolonilerin 7 ölçüm döneminde saptanan arılı petek sayıları Çizelge 2'de sunulmuştur. Kitlesel kışlatılan ana arıların test kolonilerinde sergiledikleri yumurtlama performansı (arılı petek sayıs1) bireysel kışlatılanlardan farklı bulunmamıştır $(\mathrm{P}>0.05)$. Ana arı genotipleri arasında farklar önemsiz $(\mathrm{P}>0.05)$, dönemler arası farklar ise önemli $(\mathrm{P}<0.01)$ bulunmuştur.

Bu çalışmada, ABK ve ASBK'de depolanan ana arılardan yaşayanların oranı bazı araştırıcıların bulduğu değerlerden düşük (Levinsohn \& Lensky 1981; Dietz 1983) bazı araştırıcıların (Wyborn et al 1998; Gençer 2003) bulduğu değerden ise yüksek bulunmuştur. Farklı iklim koşullarının, banka kolonilerindeki farklı uygulamaların, banka kolonisininizolasyonu, anaarıdepolamaçerçevesinin boyutları, ballık ya da kuluçkalıktaki pozisyonu gibi birçok uygulama farklılı̆̆ının, yaşayan ana arıların oranını etkilediği bildirilmektedir (Levinsohn \& Lensky 1981; Wyborn et al 1998; Gençer 2003). Örneğin karasal iklim koşullarında Gençer (2003), ana arılı banka kolonilerinde ana arıları kitlesel kışlatmanın başarısız olduğunu, ana arısız banka kolonilerinde ise 2 farklı uygulamada \% 40.5 ve $\% 16.7$ 'sinin 5 ay yaşadığını bildirmiştir.

$\mathrm{Bu}$ çalışmada, yaklaşık 3 aylık depolama sonunda, ABK'de kışlatılan ana arıların \% 15-25 
Çizelge 2- Çiftleştirme kutuları, banka kolonileri ve ruşetlerde kışlatılmış ana arılar ile yönetilen test kolonilerinin farklı dönemlerde arılı petek sayıları

Table 2- The number of combs covered with bees in test colonies headed by queens overwintered in mating boxes, reservoir colonies and 5-frame nucleus colonies in different periods

\begin{tabular}{llllllll}
\hline \multirow{2}{*}{ Dönem } & \multicolumn{2}{c}{ Çiftleştirme kutusu } & \multicolumn{2}{c}{ Banka kolonisi } & \multicolumn{2}{c}{ Ruşet (kontrol) } & \multirow{2}{*}{ Genel } \\
\cline { 2 - 7 } & $\begin{array}{l}\text { It } \\
(n=5)\end{array}$ & $\begin{array}{l}A E \\
(n=5)\end{array}$ & $\begin{array}{l}\text { It } \\
(n=5)\end{array}$ & $\begin{array}{l}A E \\
(n=5)\end{array}$ & $\begin{array}{l}\text { It } \\
(n=5)\end{array}$ & $\begin{array}{l}A=5) \\
(n=0.60\end{array}$ \\
\hline 19.04 .13 & $8.1 \pm 0.60$ & $8.2 \pm 0.60$ & $8.4 \pm 0.60$ & $8.0 \pm 0.60$ & $8.0 \pm 0.60$ & $7.8 \pm 0.60$ & $8.1 \pm 0.08^{\mathrm{A}}$ \\
10.05 .13 & $11.6 \pm 0.60$ & $10.3 \pm 0.60$ & $11.7 \pm 0.60$ & $10.4 \pm 0.60$ & $11.0 \pm 0.60$ & $10.1 \pm 0.60$ & $10.9 \pm 0.21^{\mathrm{B}}$ \\
31.05 .13 & $12.9 \pm 0.60$ & $12.8 \pm 0.67$ & $13.2 \pm 0.60$ & $12.4 \pm 0.60$ & $12.6 \pm 0.60$ & $11.5 \pm 0.60$ & $12.6 \pm 0.29^{\mathrm{CE}}$ \\
21.06 .13 & $14.0 \pm 0.60$ & $14.3 \pm 0.67$ & $14.4 \pm 0.60$ & $13.8 \pm 0.60$ & $14.2 \pm 0.60$ & $14.2 \pm 0.60$ & $14.1 \pm 0.29^{\mathrm{D}}$ \\
12.07 .13 & $11.8 \pm 0.67$ & $13.3 \pm 0.67$ & $12.8 \pm 0.67$ & $13.8 \pm 0.67$ & $14.1 \pm 0.60$ & $13.8 \pm 0.60$ & $13.3 \pm 0.37^{\mathrm{CD}}$ \\
02.08 .13 & $10.8 \pm 0.67$ & $11.3 \pm 0.67$ & $12.6 \pm 0.78$ & $11.0 \pm 0.78$ & $12.0 \pm 0.60$ & $11.3 \pm 0.60$ & $11.5 \pm 0.24^{\mathrm{BE}}$ \\
23.08 .13 & $10.0 \pm 0.67$ & $10.5 \pm 0.67$ & $11.7 \pm 0.78$ & $10.3 \pm 0.78$ & $10.8 \pm 0.67$ & $10.8 \pm 0.60$ & $10.6 \pm 0.21^{\mathrm{B}}$ \\
\hline Genel & $11.3 \pm 0.24$ & $11.5 \pm 0.25$ & $12.1 \pm 0.25$ & $11.4 \pm 0.25$ & $11.8 \pm 0.23$ & $11.3 \pm 0.24$ & \\
\hline
\end{tabular}

A, B, C, D, E: P<0.01, It, Italyan; AE, Anadolu arısı Ege ekotipi

gibi az bir kısmının yaşadığı belirlenmiştir. $\mathrm{Bu}$ sonuç, Ege Bölgesi'nde ABK'de uzun süre kitlesel kışlatmanın başarısız olduğunu göstermiştir. ABK'de ana arının kış aylarında yumurtlamaya çok kısa süre ara vermesi, bakıcı işçi arıların depolanan ana arıları ihmal etme olasılığını artırmaktadır. Benzer iklim koşullarında yapılan bir çalışmada (Levinsohn \& Lensky 1981), mayıs-ağustos ayları arasında ABK'de bankalanan ana arıların 1 ay sonunda \% 83'ünün yaşadığı, 2 ay sonunda ise \% 78'inin yaşadığı saptanmıştır. Bu çalışmanın yapıldığ 1 arılıkta da yaklaşık 10 yıldır yetiştirilen ana arıların elde tutulması amacı ile mayıs-ağustos ayları arasında zaman zaman ana arılı kolonilerde 2-3 ay gibi uzun süre depola uygulamalarında önemli düzeyde ana arı kaybı yaşanmamıştır.

Wyborn et al (1993) kışı sert geçen bölgelerde yalıtıma bağlı olarak, banka çerçevesindeki ana arı sayısının ve ana arının çerçevedeki konumunun önemli olduğunu, merkeze yakın ana arıların yaşama şansının daha yüksek olduğunu belirtmiştir. $\mathrm{Bu}$ çalı̧̧mada da, depolama çerçevesine farklı genotipler dizilirken buna dikkat edilmiştir. Banka çerçevesinde bulunan kafes bloğunun merkezindeki kafeslerde kenardaki kafeslere göre daha az sayıda ana arının öldüğü gözlenmiştir.
Çalışmada, çiftleştirme kutularında bireysel kışlatma (\% 100, \% 100), ASBK'de kitlesel kışlatmaya (\% 64.3 ve $\% 71.5)$ göre daha başarılı bulunmuştur. Bu sonuçlara göre, bölge koşullarında çiftleştirme kutularında bireysel kışlatma yapmak bilgi beceri gerektirmemesi ve kolay olmas1 bakımından daha avantajlı görünmektedir. $\mathrm{Bu}$ çalışmada her banka kolonisinde 14 ana arı bankalanmıştır. Çok güçlü hazırlanan bir ASBK'de ise 24-48 arasında ana arı bankalanabilir (Wyborn et al 1993). Çok sayıda ana arıyı bireysel kışlatmak besleme ve bakım işlerini artıracağı için daha çok zaman alıcı olabilir. Bu nedenle sonbaharda çok sayıda ana arı kışlatmak isteyen ana arı yetiştiricileri \% 25-30 ana arı kaybını göze alarak çok sayıda ana arıyı bir kaç banka kolonisinde kışlatabilirler.

Çalışmada, her 2 yılda da çiftleştirme kutularında kışlatılan ana arıların yaşama oranının (\% 100), karasal iklim koşullarında, çiftleştirme kutularında kışlatılan ana arıların yaşama oranlarından (\% 80.0 ve \% 83.3; Gençer 2003) daha yüksek bulunması, bölgenin 1lıman iklim özelliklerinden kaynaklanabilir. Banka kolonileri ve çiftleştirme kutularında kışlatılmış ana arılar ile oluşturulan test kolonilerinin gelişimlerinin kontrol grubu kolonilerden farklı olmaması, kitlesel kışlatmanın 
ana arıların yumurtlama performanslarını olumsuz etkilemediğini göstermiştir. $\mathrm{Bu}$ sonuç Shehata (1982), Wyborn et al (1993) ve Gençer (2003)'in bulgularıyla uyuşmaktadır.

\section{Sonuç}

Ege Bölgesi ekolojik koşulları nedeniyle uzun dönem ana arı yetiştiriciliğine uygundur. Bölgede ana arı işletmelerinin yetiştirdikleri ana arılardan, sonbaharda elde kalanları bireysel olarak çiftleştirme kutularında ya da kitlesel olarak ana arısız banka kolonilerinde erken ilkbahara kadar depolamaları karlılığı artıracaktır.

Sonuç olarak, ana arı yaşama gücü bakımından bireysel kışlatma kitlesel kışlatmaya göre, kitlesel kışlatmada da ana arısız banka kolonileri ana arılı banka kolonilerine göre daha başarılı olmuştur. Ancak, sonbaharda ana arı üretim işletmelerinde pazarlanmamış ana arılar kalması durumunda, işletmelerin \% 25-30 ana arı kaybını göze alınarak bu ana arıları ana arısız banka kolonilerinde depolamaları mümkündür.

\section{Teşekkür}

Bu araştırmaya ZRF 10004 ve ZRF 14026 numaralı projeler aracılığı ile finansal destek sağlayan ADÜBilimsel Araştırma Proje Komisyonu'na ve verilerin istatistik analizine yardımcı olan Prof. Dr. Kadir KIZILKAYA'ya teşekkür ederiz.

\section{Kaynaklar}

Dietz A, Wilbanks T W \& Wilbanks W G (1983). Investigations on long term queen storage in a confined system. Apiacta3, http://www.apimondiafoundation. org/foundation/files/1983/A.\%20DIETZ,\%20 T.W.\%20 WILBANKS,\%20W.G.\%20WILBANKS. pdf (Erişim tarihi: 24 Ocak 2013)

Gençer H V (2003). Overwintering of honey bee queens en mass in reservoir colonies in a temperate climate and its effect on queen performance. Journal of Apicultural Research 42(4): 61-64

Levinsohn M \& Lensky Y (1981). Long-term storage of queen honeybees in reservoir colonies. Journal of Apicultural Research 20(4): 226-233

Shehata S M (1982). Long-term storage of queen honeybees in isolation. Journal of Apicultural Research 21(1): 11-18

Uçak-Koç A \& Karacaoğlu M (2004). Effects of rearing season on the quality of queen honeybees (Apis mellifera L.) raised under the conditions of Aegean Region. Mellifera, Türkiye Arıcılık Dergisi 4(7): 3437

Uçak-Koç A \& Karacaoğlu M (2005). Anadolu arısı Ege ekotipi (A. m. anatoliaca) ana arılarında üreme özellikleri. ADÜ Ziraat Fakültesi Dergisi 2(1): 73-77

Uçak-Koç A \& Karacaoğlu M (2011). Effects of queen rearing period on reproductive features of Italian (Apis mellifera ligustica), Caucasian (Apis mellifera caucasica), and Aegean ecotype of Anatolian honey bee (Apis mellifera anatoliaca) queens. Turkish Journal of Veterinary and Animal Sciences 35(4): 271-276

Woyke J (1988). Problems with queen banks. American Bee Journal 128(4): 276-278

Wyborn M H, Winston M L \& Laflamme P H (1993). Mass storage of honey bee (Hymenoptera: Apidae) queens during the winter. The Canadian Entomologist 125(1): 113-128 